Article

\title{
Discrete Element Modelling of Footwall Rock Mass Damage Induced by Sub-Level Caving at the Kiirunavaara Mine
}

\author{
Mikael Svartsjaern * (1) and David Saiang \\ Department of Civil, Environmental and Natural Resources Engineering, Luleå University of Technology, \\ Laboratorievägen, Luleå 97187, Sweden; david.saiang@ltu.se \\ * Correspondence: mikael.svartsjaern@ltu.se; Tel.: +46-920-491906
}

Received: 22 May 2017; Accepted: 20 June 2017; Published: 23 June 2017

\begin{abstract}
The Kiirunavaara mine is one of the largest sub-level-caving (SLC) mines in the world and has been in underground operation for more than 50 years. The mine has been the focus of several case studies over the years. The previous works have either focused on the caving of the hanging wall, using the footwall as a passive support, or focused on the footwall using the hanging wall to apply a passive load. In this updated study the findings of the previous case studies are combined to study the interaction between the caving hanging wall, the developing cave rock zone and the footwall. The geological data for the rock types in the mine area are used to derive upper and lower limits for the geomechanical parameters calibrated for numerical models in the previous studies. The calibrated parameters are used as inputs to a numerical model constructed using Itasca's Particle-flow-code (PFC) encompassing a mine-scale 2D section at the mid portion of the mine. The model captures the failure locations well in the footwall underground and indicates damage development without a coherent large-scale failure. The trend in subsidence data on the hanging wall is adequately simulated but the magnitude of deformation is underestimated. The input strength for the hanging wall was lowered to study the impact of hanging wall strength on footwall damage development. It is shown that when the footwall strength is kept constant, while lowering the hanging wall strength, the extent of damage and magnitude of displacements in the footwall increases. From these observations it is argued that the hanging wall and footwall cannot be studied independently for the Kiirunavaara mine since the cave rock zone significantly affects the damage development in both walls.
\end{abstract}

Keywords: Kiirunavaara; PFC; case study; mine-scale; rock mass damage; numerical modelling

\section{Introduction}

A well-established fact is that large-scale mining affects the rock mass at a considerable distance from the actual mining area, especially in the case of large-scale underground mining. A common problem, however, is that even though the effect of the underground mining might be evident from surface settlements or lowering of ground water, the explicit behaviour of the rock mass can seldom be directly studied. The underground environment, except for the immediate production area, is often inaccessible and, with the possible exception of seismic arrays, void of monitoring equipment.

The Kiirunavaara mine offers a rare opportunity for studying the rock mass behaviour away from mining. The mineralisation is concentrated in a tabular orebody with a $60^{\circ}$ dip that is mined by sub-level-caving (SLC). The transition from open pit into underground mining by SLC at the end of the 1950s has had a significant impact on the ground surface footprint, with caving and surface settlement on the hanging wall and caving of a cap rock above the lake ore, which was not mined during the open pit operation (see Figure 1). Aside from the lake ore area, the surface impact on the footwall has been small, with tensile crack formation and discontinuous deformation confined to the 
old open pit walls [1]. The apparent difference in behaviour between the hanging wall and footwall has resulted in the two volumes being studied almost separately. A number of previous studies focus on the ground surface impact from mining using the hanging wall rock mass as the primary entity of study, with the footwall as a passive support with a minimum of calibration related to the footwall behaviour (later works include, e.g., Villegas and Nordlund [2,3]). A second set of studies concentrates on the underground rock mass response and the impact on underground mining infrastructure, with the footwall rock mass in focus with hanging wall supplying buttress pressure with a minimum of calibration related to hanging wall ground surface response (later works include, e.g., Henry and Dahnér-Lindqvist [4] and Svartsjaern et al. [5]).

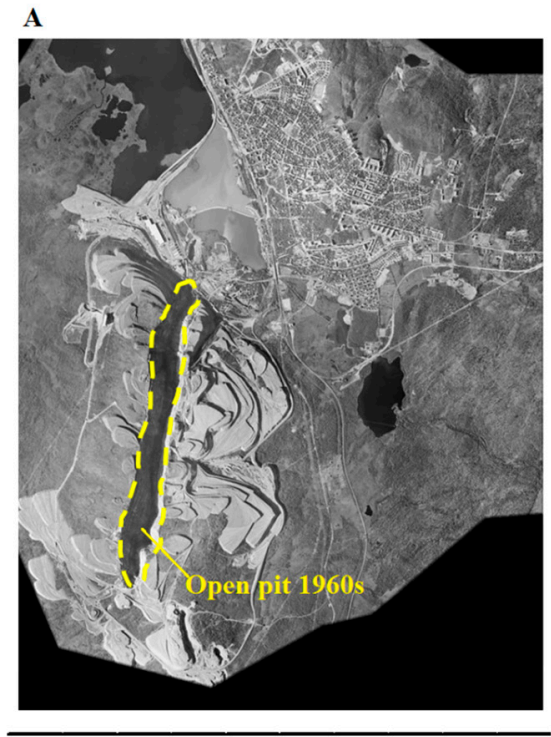

$5 \mathbf{~ k m}$

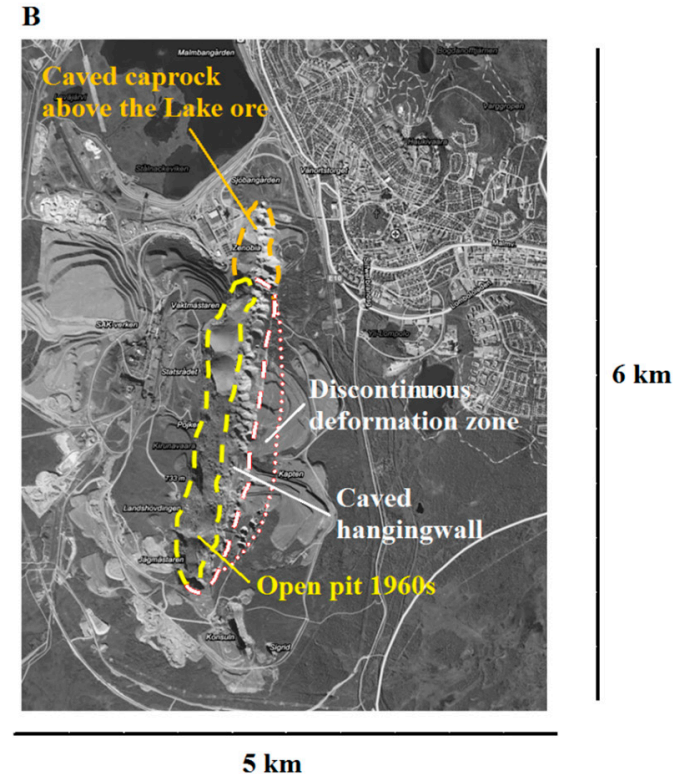

$5 \mathbf{~ k m}$

Figure 1. Ground surface footprint of mining operations: (A) aerial photograph captured during the 1960s and (B) aerial photograph captured after 2010. Adapted from Eniro [6].

The combination of scale, geometry and mining method has resulted in a vast network of decommissioned infrastructure being left behind in the footwall as mining advanced. This allows the footwall to be inspected at a variety of depths, from the active production levels all the way up to the ground surface, meaning that the development of damage and displacements can, in some respect, be directly observed inside the rock mass. Based on underground observations and back analysis by numerical modelling, Svartsjaern et al. [5] suggested that while the rock mass in the footwall underground is damaged, there is no explicit footwall or slope failure in progress, i.e., there is general damage without a specific large-scale failure. This theory is also supported by the results from Sjöberg [7], where large-scale models of the footwall required significantly lowering the rock mass input values to achieve large-scale failure. That means that capturing the damage development in the footwall underground requires the study of small-scale damage mechanisms at a large scale, rather than expecting large-scale mechanisms in a coherent failure. On the hanging wall, Villegas et al. [8] and Villegas and Nordlund [3] describe the surface subsidence to include a discontinuous zone with formation of tensile fractures at the ground surface, step-like settlement, and toppling of newly formed blocks near the old open pit rim. The failure mechanisms underlying such behaviour require the represented material to be allowed to fail at any point and form new fractures in previously undisturbed material.

How to include the action of the hanging wall caved rock mass on the footwall and surface profile development has also been a matter of concern. Lupo [9] simulated the action of the cave using equivalent surface tractions derived from silo-theory. Sjöberg [7] and Villegas and Nordlund [3] 
represented the caved rock as a low-stiffness continuum material and Svartsjaern et al. [5] used the same approach but allowed for slip and complete detachment along the footwall-cave rock interface.

To account for the points raised above, the current study uses the Bonded-Particle Model (BPM) in PFC2D 5.0 [10] to allow for new fracture propagation through a homogeneous rock mass matrix and direct inclusion of the cave rock. As bonds break between particles in the hanging wall due to the mining advance, the cohesive rock mass matrix constituting the hanging wall breaks down into a frictional, zero tensile strength material made up of the unbounded particles that cave into the void left by ore extraction. As the BPM allows for tracking individual bond breakages (fracture formations), damage to the footwall rock mass can be studied even if no distinct large-scale failures develop.

On the hanging wall, the close proximity of the caving operation to the city of Kiruna has resulted in ground surface subsidence being monitored and documented in great detail for decades, producing a vast bank of ground deformation data. These data have been used as a benchmark for various ground deformation analyses at the mine. This paper utilizes the data from both the footwall and hanging wall gathered over the last decades to study the mine-scale impact on the rock mass from mining and the co-dependence between the two walls for the system behaviour.

\section{Site Description}

The Kiirunavaara mine, or Kiruna mine, located near the city of Kiruna in the county of Norrbotten in northern Sweden, is owned and operated by the state-owned stock company Luossavaara-Kiirunavaara Aktiebolag (LKAB). Mine operations date back to the early 1900s, with a transition from open pit to underground mining in the 1950s. Current annual production is in the range of 28 million tonnes of iron ore per year. The northernmost part of the currently mined volume was never exploited by the open pit operation. This northern extension of the ore is named the lake ore and underground-only access resulted in a ground surface footprint by caving of the lake ore cap-rock (Figure 1B).

\subsection{Mine Layout}

The underground mine can be described as three principal parts; (i) the northern part with Y-coordinates 9-21, including the lake ore, (ii) the central facilities area (CA-area) hosting the life of mine infrastructure at Y21-25; and (iii) the southern part comprising Y-coordinates 25-50. The production areas in the respective parts are divided into production blocks roughly $400 \mathrm{~m}$ wide, named by the centre Y-coordinate. The principles of the underground layout are shown in Figure 2.

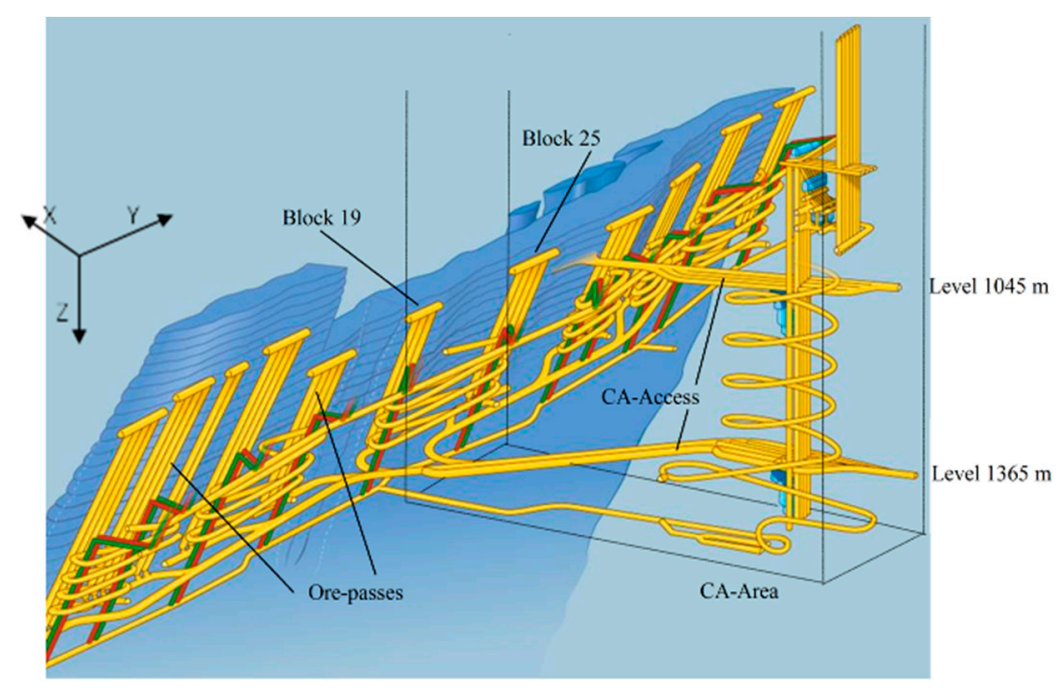

Figure 2. Principal layout of the underground mining infrastructure as seen from the footwall. Image courtesy of LKAB. 
Ore extraction is achieved by blast-induced caving from silo-shaped production rings consisting of up to $50 \mathrm{~m}$ long holes with a diameter of $115 \mathrm{~mm}$. The current sublevels are separated by a $28 \mathrm{~m}$ vertical distance and developed with a relative offset of $12.5 \mathrm{~m}$ (cross cut spacing is $25 \mathrm{~m}$ ) to allow for the corresponding production rings. The sublevel height has been upscaled three times since underground production began, namely in $1963(9 \mathrm{~m}), 1983(12 \mathrm{~m})$, and 1995 to the current $28 \mathrm{~m}$.

The current main haulage level is $1365 \mathrm{~m}$, though a few remaining blocks still use the previous main haulage level located at $1045 \mathrm{~m}$. Production in the main orebody is performed between levels 993 and $1051 \mathrm{~m}$ depending on the production block. Level designations use an artificial ground surface as the origin based on the pre-mining peak of the Kiirunavaara mountain peak. With the current ground surface undulating and the footwall crest towering well above the hanging wall crest, the actual depth from ground surface and mining level designations may differ by as much as $200 \mathrm{~m}$.

The tabular nature of the Kiirunavaara orebody makes it possible to study various sections of the mine as 2D transverse (east-west) sections. The elongated geometry creates near plane strain conditions at the mine scale for the middle two-thirds of the orebody length, as shown by numerical stress analyses by Malmgren and Sjöberg [11]. As for the general rock mass response, section Y23, located in the middle of the CA-area, provides the most comprehensive dataset of underground observation points. The profile also represents one of the most crucial sections from a stability point of view as the CA area includes the main decline system and a number of support infrastructure installations.

The state of stress in the mining area is characteristically highly non-uniform. Due to the large and long-term mining operations, the difference between virgin and secondary stresses is significant regarding both orientation and magnitude. The major primary principal stress acts perpendicular to the orebody and thus the footwall; as a result, secondary stresses tend to concentrate at the footwall slope toe beneath the production level. The stress measurements conducted in the Kiirunavaara mine before 2003 have been summarised by Sandström [12].

\subsection{Geological Setting}

The geology of the mine area is composed of igneous and metamorphic rocks, which are part of the Fennoscandian Shield. A ductile foliation that strikes north-south is commonly encountered within the area. A number of weakness zones align with this regional foliation, which shows signatures of hydrothermal alteration, including deposition of chlorites. Both the orebody itself and the principal rock type boundaries in the footwall and hanging wall sides align with the strike of the regional structures [13].

The rock mass directly to the west of the footwall contact is interpreted as Precambrian aged tracho-andesites, locally referred to as syenite porphyries, Figure 3. These syenite porphyries have historically been separated into five subgroups denoted SP $1-5$ based on core test results. The subgroups do not cluster but are to a large degree intermixed. This intermixing, combined with the large variation in geomechanical properties between the subgroups, makes field estimations of the rock mass properties at any given location difficult. 


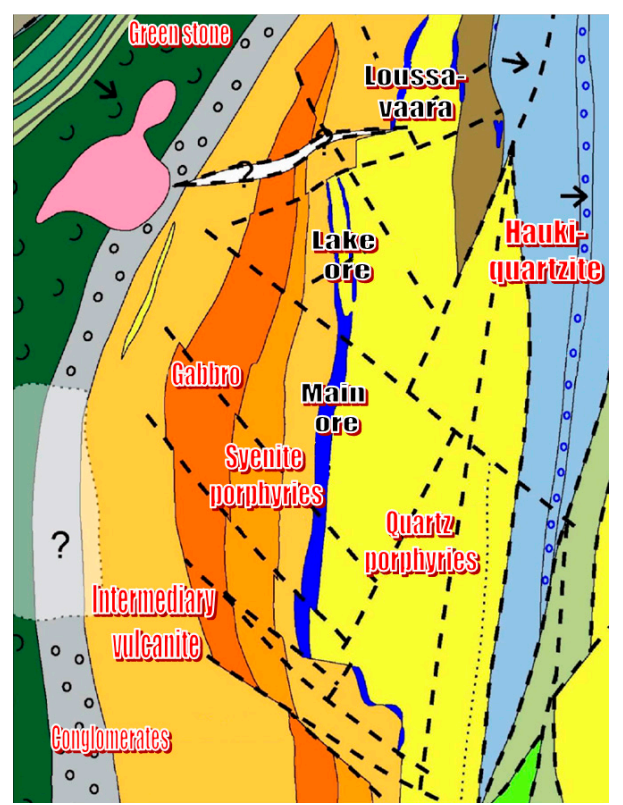

Figure 3. Map of Kiirunavaara near-surface geology; dashed lines indicate interpreted possible deformation zones. Adapted from Mattson et al. [13].

The most commonly occurring subgroup is SP1, which forms the "baseline" syenite porphyry. SP3 has a high content of amygdules and occurs more commonly close to the footwall contact. The footwall ore contact also contains $0.2-0.4 \mathrm{~m}$ thick zones of amphibolite and actinolite skarns. SP4 and 5 are intermixed in volumes of SP1, where SP4 is considered to be more competent and SP5 represents heavily weathered rock. Laboratory tests of cores indicate a range of intact uniaxial compressive strengths (UCS) from $90 \mathrm{MPa}$ for SP5 to $430 \mathrm{MPa}$ for SP4, with SP1 falling around $300 \mathrm{MPa}$ and SP3 showing considerable spread but generally falling within 110-210 MPa [14]. Intact rock core strength data, including the results from point load tests compiled by Vatcher et al. [15], also show that there is considerable spread in the strength properties within the remaining subgroups SP1, 2, 4, and 5.

Farther westward from the footwall, a competent granite dome is mapped on levels below $800 \mathrm{~m}$. Documentation of the rock mass at a distance from the ore contact is limited to drift mapping, primarily for the central region, as most cores are related to the prospecting of mineable ore and limited attention has been given to the host rock housing the infrastructure.

The first layer of the hanging wall rock near the ore contact constitutes pyroclastic rhyodacites referred to as quartzite-porphyry [8]. As for the footwall, the hanging wall main group (quartzite-porphyry) is locally split into five subgroups designated QP1-5. Again, as in the footwall, the internal distribution of QPs for a given volume is complex, with a high degree of intermixing. QP1-3 represent baseline quartzite-porphyry, differentiated mainly by colour and mineral content, with QP3 having a high chlorite and amphibole content. QP4 is interpreted as a meta rhyodacite and QP5 represents heavily weathered rock [16]. From the laboratory data, there is no significant difference in strength properties between the QP groups [15]; however, it is reasonable to assume that QP5 (similar to SP5) would represent significantly lower strength. The hanging wall is in general considered to be less competent than the footwall (e.g., [3,15]).

The orebody strikes north-south with an eastwards dip of about 60 degrees and is roughly parallel to the orientation of the ductile regional deformation foliation. The tabular orebody constitutes a fine-grained magnetite with intrusions of apatite with a variable width of anything from a few meters to $200 \mathrm{~m}$ but averaging $80-90 \mathrm{~m}$. The continuation of the orebody at depth is unknown. Current and previous mining show a gentle dip-along-strike towards the north, extending the footprint of the SLC away from the old open pit. In general, the ore is considered less competent than the host rock, with the exception of SP5 and contact minerals. 
Information about dominant joint orientations has been documented for most levels in moderate detail; however, joint properties have in general not been recorded. The dominant joint orientation has historically motivated the separation of the length of the footwall into domains. These domains cannot be clearly traced between levels, even though some similarities are observed between main haulage levels. The continuation of previous patterns down to level $1365 \mathrm{~m}$ has been deemed uncertain. Work by Vatcher et al. [15] indicate that, at a mine scale, the domains for the rock joints might not be well represented by 2D sections related neither to the mine length coordinate (Y-axis) nor the depth designation by mining level (Z-axis). Joint orientation distribution in the southern portion of the mine (primarily in the footwall south of Y28) is reported as having a large random component and clustering of joint sets into domains is uncertain. In both the northern and southern extents of the mine, joint sets dipping parallel or sub-parallel to the orebody can be found following the general trend of the regional structures. In general the joints do not cross the ore contact zones, even though the major orientations are roughly the same on both sides of the contact [13].

\subsection{Current Deformation State of the Hanging wall and Footwall}

On the hanging wall the ground surface footprint develops in two main stages of ground settlement: a continuous deformation zone (free of tensile cracks and steps) and a discontinuous deformation zone. The discontinuous deformation zone is characterised by tensile fractures forming on the ground surface; these fractures develop into steps of discontinuous deformation closer to the pit rim and include complete caving of the old open pit hanging wall. Figure 4 illustrates the definitions used for the ground surface deformation zones at the mine. The angle between the farthest point from mining (horizontal distance on ground surface) in the continuous deformation zone and the current mining level is defined as the limit angle and the transition point into the discontinuous deformation zone is given by the break angle.

The footwall rock mass response to mining is most noticeable underground in the decommissioned mining infrastructure overlying the current production areas. Svartsjaern et al. [17] divided the rock mass closest to the ore contact in the footwall, based on results from damage mapping of the decommissioned infrastructure and numerical modelling, into two conceptual zones: (i) a damaged zone near the ore contact, where damage to the infrastructure is common and systematic; (ii) an undamaged zone with no significant damage to the infrastructure. In the undamaged zone infrastructure damage is sporadic and judged to be primarily caused by local variation in rock strength rather than stress redistribution or deformation. The damage in the damaged zone is most severe close to the ore contact and lessens farther into the footwall. The conceptual transition between damaged and undamaged is defined as a damage extent boundary (DEB). The boundary does not represent a physical plane but a transitional border. Infrastructure located between the ore contact and the boundary has a high probability of having sustained systematic damage, while infrastructure outside the boundary is unlikely to have suffered damage unrelated to local rock mass deterioration by, e.g., clay zones or water inflow. In most locations the location of the DEB, and nearby damage, can be correlated to natural pre-existing structure sets. The concepts of the described rock mass responses to mining for the hanging wall and footwall is visualised in Figure 4. The rock mass movements interpreted for the footwall underground from the mapped infrastructure damage cannot be detected from ground surface monitoring. The current theory is that the underground movements are redirected towards the open pit slope by sub-vertical structure sets near the ground surface. Evidence of such structures includes the results from underground mapping and structures that directly daylight in the open pit footwall slope. 


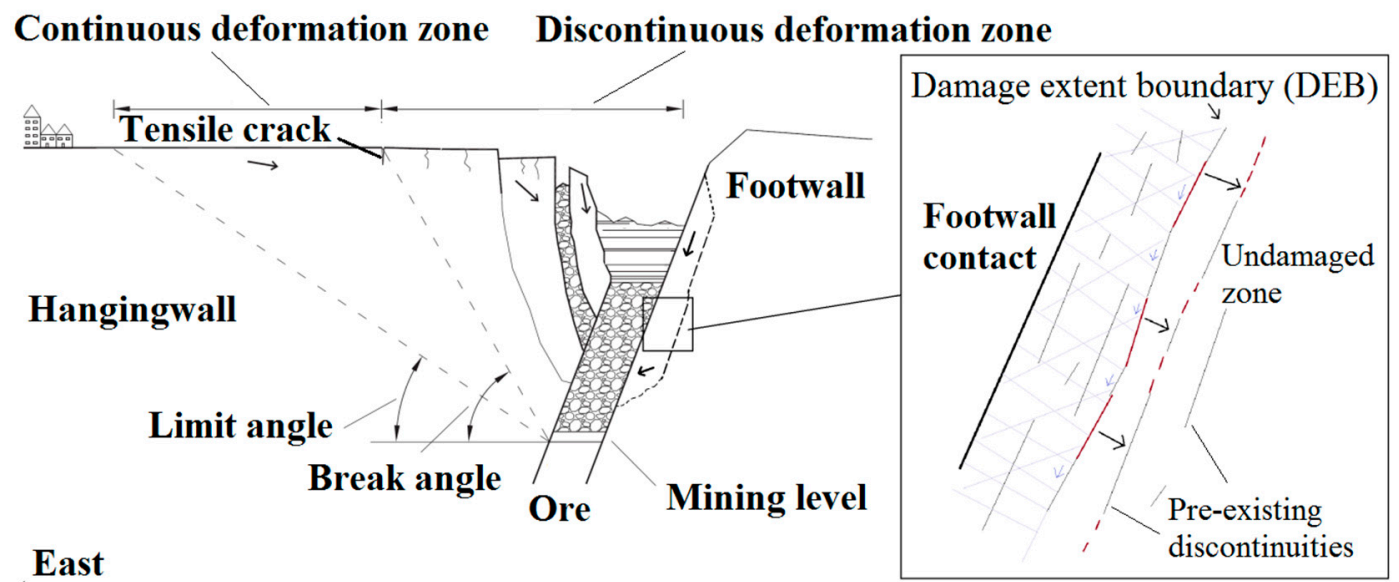

Figure 4. Concept of underground rock mass response to mining. Adapted from Villegas et al. [8] and Svartsjaern et al. [5].

\section{Modelling Approach}

In all studies of large-scale rock masses, a simplified representation of the in situ material is required. The relatively well-known properties of the small-scale intact material need to be combined with the, in general poorly known, properties of the large-scale system of intact material, brittle fractures, ductile structures and more or less random heterogeneities such as clay zones and intrusions. This results in a common use of equivalent homogeneous material representations such as Mohr-Coulomb materials. This type of representation works well when heterogeneities are small in relation to the studied scale. Specific large impact in-homogeneities can be overlaid on the material, but the creation of new structures as a response to loading is in general not permitted. An alternative approach is the use of a synthetic rock mass (e.g., Mas Ivars [18]). The synthetic rock mass represents the in situ material in more detail by a matrix of intact material composed of glued-together particles and statistically or explicitly generated discontinuity planes representing rock joints. New fractures can form either along the discontinuity planes or through the intact material matrix by breaking the glued bonds between the constitutive particles. An example of this is the Bonded-Particle Model (BPM) developed by Potyondy and Cundall [19] and included in Itasca's Particle Flow Code (PFC) with the argument that both intact rock and rock masses can be described as cemented granular materials. In the BPM the granular material is represented by indestructible spherical (3D) or disc-shaped (2D) particles. The particles have no internal properties save density; particle interaction is governed solely by contact properties related to the particle "surface". Deformation of a matrix is achieved by separation or overlap of individual particles. The particles can be bonded together by a set of breakable springs creating a cohesive and frictional bond with a separated tensile strength not directly related to the cohesion. As a bond is broken, further contact interaction is governed by particle surface friction and overlap stiffness. The BPM thus simulates both peak and post-peak properties of a material, where new fracture formation is allowable by systematic bond breakage. For this study, a combination of equivalent rock mass properties from back analysis cases was used to calibrate the BPM after using field data to estimate acceptable property ranges.

\subsection{Rock Mass Strength Properties from Back Analysis Studies}

Unlike for the intact material, the properties of the rock mass cannot be directly determined by standardized testing approaches. The rock mass involves scales too large for replication in a laboratory environment and a great number of unknowns in the field. A common approach is therefore to derive equivalent rock mass parameters for a studied volume by back analysis. This type of analysis can be based on scaling intact material properties using empirical relationships and field observations such as 
the degree of jointing and interlocking. The equivalent rock mass strength used in previous studies of the Kiirunavaara hanging wall and footwall studies are summarized in Table 1.

Table 1. Rock mass strength input used in earlier studies for footwall (FW) and hanging wall (HW).

\begin{tabular}{|c|c|c|c|c|}
\hline Source & Type of Study & Focus & $\begin{array}{c}\text { Rock Mass Cohesion } \\
(\mathrm{MPa}) \text { and Internal } \\
\text { Friction Angle }\left(^{\circ}\right)\end{array}$ & $\begin{array}{c}\text { Indicated } \\
U C S_{r m} \text { Using } \\
\text { Equation (1) }\end{array}$ \\
\hline Dahnér-Kindqvist [20] & $\begin{array}{l}\text { Limit equilibrium } \\
\text { by empirical charts }\end{array}$ & Footwall stability & $\begin{array}{l}c=1.5 \\
\phi=30\end{array}$ & $5.2 \mathrm{MPa}$ \\
\hline Singh et al. [21] & $\begin{array}{l}\text { Numerical study in } \\
\text { FLAC }\end{array}$ & $\begin{array}{l}\text { Deformation and } \\
\text { failure of both } \\
\text { Footwall and } \\
\text { hanging wall }\end{array}$ & $\begin{array}{c}c=2.0-8.6 \\
\phi=30\end{array}$ & $6.9-30 \mathrm{MPa}$ \\
\hline Lupo [9] & $\begin{array}{c}\text { Calibrated } \\
\text { numerical study in } \\
\text { CAV7 }\end{array}$ & $\begin{array}{l}\text { Hanging wall and } \\
\text { footwall behaviour }\end{array}$ & $\begin{array}{c}\text { HW } \\
c=1.13 \phi=37 \\
\text { FW } \\
c=1.18 \phi=37\end{array}$ & $\begin{array}{c}\mathrm{HW} \\
4.5 \mathrm{MPa} \\
\text { FW } \\
4.7 \mathrm{MPa}\end{array}$ \\
\hline Lupo [22] & $\begin{array}{c}\text { Numerical study in } \\
\text { FLAC }\end{array}$ & $\begin{array}{l}\text { Hanging wall and } \\
\text { footwall }\end{array}$ & $\begin{array}{l}c=1.2 \\
\phi=37\end{array}$ & $4.8 \mathrm{MPa}$ \\
\hline Sjöberg [7] & $\begin{array}{c}\text { Calibrated } \\
\text { numerical study in } \\
\text { FLAC }\end{array}$ & $\begin{array}{l}\text { Footwall stability } \\
\text { with calibration } \\
\text { towards inducing } \\
\text { failure }\end{array}$ & $\begin{array}{c}c=1.3 \phi=34.8 \\
\text { Calibrated to } \\
c=0.1-0.8 \text { and } \phi=30-40\end{array}$ & $\begin{array}{c}4.99 \mathrm{MPa} * \\
0.43-2.77 \mathrm{MPa}\end{array}$ \\
\hline $\begin{array}{c}\text { Henry and } \\
\text { Dahnér-Lindqvist [4] }\end{array}$ & $\begin{array}{l}\text { Numerical study in } \\
\text { FLAC }\end{array}$ & Footwall stability & $\begin{array}{c}c=0.6 \\
\phi=30\end{array}$ & $2.3 \mathrm{MPa}$ \\
\hline $\begin{array}{l}\text { Sitharam and Madhavi } \\
\text { Latha [23] }\end{array}$ & $\begin{array}{l}\text { Numerical study in } \\
\text { FLAC }\end{array}$ & Footwall stability & $\begin{array}{c}\mathrm{HW} \\
c=1.0 \phi=35 \\
\mathrm{FW} \\
c=0.6 \phi=35\end{array}$ & $\begin{array}{c}\mathrm{HW} \\
\text { 3.84 MPa } \\
\text { FW } \\
2.3 \mathrm{MPa}\end{array}$ \\
\hline Villegas and Nordlund [2] & $\begin{array}{c}\text { Numerical study in } \\
\text { PFC }\end{array}$ & $\begin{array}{l}\text { Hanging wall } \\
\text { deformation }\end{array}$ & $\begin{array}{l}c=2.7 \\
\phi=51\end{array}$ & $15.2 \mathrm{MPa}$ \\
\hline Villegas and Nordlund [3] ** & $\begin{array}{l}\text { Numerical study in } \\
\text { FLAC and PFC }\end{array}$ & $\begin{array}{l}\text { Hanging wall } \\
\text { deformation }\end{array}$ & $\begin{array}{c}c_{\text {peak }}=7.1 \phi_{\text {peak }}=47 \\
c_{\text {residual }}=1.0 \\
\phi_{\text {residual }}=37\end{array}$ & $\begin{array}{c}\text { Peak } \\
36 \mathrm{MPa} \\
\text { Residual } \\
4.0 \mathrm{MPa}\end{array}$ \\
\hline Svartsjaern et al. [5] & $\begin{array}{c}\text { Calibrated } \\
\text { numerical study in } \\
\text { UDEC }\end{array}$ & Footwall stability & $\begin{array}{l}c=1.2 \\
\phi=36\end{array}$ & $4.7 \mathrm{MPa}$ \\
\hline
\end{tabular}

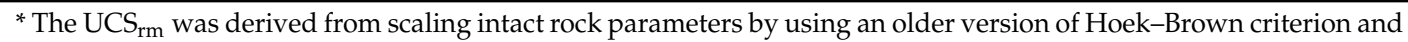
not back analysis of field damage observations. ${ }^{*}$ For the FLAC study, a brittle plastic model was implemented using both peak and residual values; the PFC study was equivalent to the study reported by Villegas and Nordlund [2].

\subsection{Rock Mass Property Ranges Using Field Data Scaling}

The high degree of intermixing between the different rock types making up the rock mass matrix, combined with the large variation in UCS results within each subgroup, makes an estimate of the rock mass strength based on the laboratory tests of rock cores alone unreliable. Even when scaled by RMR and GSI data from the field, the use of intact material properties to represent the mine-scale rock mass introduces significant uncertainty. Using the generalized Hoek-Brown criterion [24] and the same GSI range as for the elastic properties, a disturbance factor of 0.5 and $m_{i}=15$ would indicate a rock mass UCS of 9-35 MPa (Intact UCS = $200 \mathrm{MPa}$ ). This value is considerably higher than the UCS expected from Mohr-coloumb equivalent cohesion $(c)$ and internal friction angles $(\phi)$ derived from previous numerical and limit equilibrium back analyses based on field failure observations using Equation (1); see Table 1.

$$
U C S=c\left(\frac{2 \cos (\varnothing)}{1-\sin (\varnothing)}\right)
$$

In general the Mohr-coulomb equivalent rock mass properties combined with Equation (1) suggest a UCS for the rock mass $\left(\mathrm{UCS}_{r m}\right)$ of between 2 and $7 \mathrm{MPa}$. Sjöberg [7] arrived at a $\mathrm{UCS}_{r m}$ of 
4.99 MPa by scaling the intact material properties using an older version of the Hoek-Brown criterion assuming disturbed rock mass conditions in combinations with a somewhat lower intact rock strength. This value is in better agreement with the values derived by back analysis of rock mass behaviour in the field. Villegas and Nordlund [2,3] indicate higher strength properties for both the PFC study [2] and the FLAC study [3]. The FLAC study used a brittle plastic model in which the peak values were much higher than the properties used by other researchers, while the residual values match the general span. This is explained by the fact that most of the reported back analyses were based on failure or damage observations directly related to rock that has already suffered some plasticity. Villegas and Nordlund [3] attempted to study deformations on the hanging wall ahead of detectable rock mass damage and thus used high peak values to prevent early failure development. The PFC synthetic rock mass used by Villegas and Nordlund [2] included explicit jointing and the equivalent tested rock mass sample did not show a clear elastic-plastic transition or yield point. This would result in residual values near the peak values and hence the properties used by Villegas and Nordlund [2] together with Singh et al. [21] are considered to be outliers in the Table 1 summary.

The degree of jointing at Kiirunavaara is reported in terms of RMR or GSI. For the footwall Sandström [12] summarized the reported RMR values as having a range between 49 and 69 for the general rock mass, and for the hanging wall Villegas and Nordlund [3] reported a GSI of 60-80, which is roughly equivalent to a RMR of 65 . The overlap in the estimated degree of joining between the footwall and hanging wall is in line with the findings from underground mapping by Mattsson et al. [13]. The major structure orientations can be found on both sides of the ore contact zones but are not persistent through the contact itself. Field data from the underground are, due to the location of the infrastructure, much more comprehensive in the context of RMR and the range offered by the footwall data is thus considered to be a better representation of the rock mass on both sides of the orebody. Taking the footwall equivalent GSI values combined with the hanging wall GSI (combined range 54-80) and using the simplified Hoek-Diederichs equation (Equation (2); [25]), assuming a disturbance factor $(D)$ of 0.5 [3] for the un-mined rock mass, suggests a Young's modulus on the order of 3.4-25 GPa, where the upper part of the span is considered more reasonable.

$$
E_{r m}(M P a)=100000\left[\frac{1-\frac{D}{2}}{1+e^{(((75+25 D-G S I) / 11))}}\right]
$$

While a number of empirical scaling laws exist for estimating the rock mass Young's modulus, there seem to be no validated scaling laws for moving from an intact Poisson's ratio to a rock mass Poisson's ratio. However, Gercek [26] concludes from an extensive literature review of numerical studies that reported Poisson's ratios for rock masses are in general higher than for intact rocks. This is explained by the inclusion of weakness planes and random anisotropy by the included joint sets.

The Poisson's ratio of the intact rock at Kiirunavaara is reported in the range of $0.20-0.27$ for SP1, 0.14-0.27 for QP1-5 and estimated to be 0.27 for the footwall rock types as a whole by Sjöberg et al. [14]. The intact values can be used as a limit for the estimation of the rock mass Poisson's ratio [26] and a plausible range for the rock mass Poisson's ratio would then be in the order of $0-30 \%$ higher, i.e., $0.27<v>0.35$.

\subsection{PFC Model Construction and Calibration}

A model of mine section Y 23 was built by creating a box $2700 \mathrm{~m}$ wide and $2000 \mathrm{~m}$ high. The box was filled with disc-shaped particles with uniformly distributed radii between 6 and $24 \mathrm{~m}$ to a porosity of 0.15 to ensure initial tight packing and adequate filling of the "construction box". A smaller box was then cut out of the filled volume and re-filled with smaller radii particles to a porosity of 0.2 . This step was repeated three times, with the innermost box being $1200 \mathrm{~m}$ wide and $1500 \mathrm{~m}$ high and containing particles of radii between 1 and $3 \mathrm{~m}$. The particles were allowed to settle under gravity, the simplified ground surface of section Y23 was defined and particles above this surface were deleted. The model 
was again solved to equilibrium under gravitational loading and any particles rebounding above the ground surface were deleted. The final model geometry is shown in Figure 5; note that the box size indicated in the figure refers to post-ground surface cut height. The size regions for the particles were implemented to reduce run time. The hanging wall ground surface was simplified as a level surface; the landfills added to the hanging wall crest during mining evident in Figure 1 were not included. The footwall slope angles were the same as those used by Lupo [9] and the open pit floor was set at the current level. Joint sets were not explicitly modelled as the particle radii in the innermost box are similar to the in situ joint spacing; the influence of jointing was instead accounted for by using the scaled rock mass strength values for the BPM.

A direct measurement of the in situ virgin stress is not available due to the early start of operations at the mine but, based on the surrounding area and the analyses of Sandström [12], the virgin stress state can be estimated by two horizontal components and one vertical. The virgin in-plane stress ratio for a transverse section in the middle two-thirds of the orebody $\sigma_{v} / \sigma_{H}$ is estimated to be 0.78 .

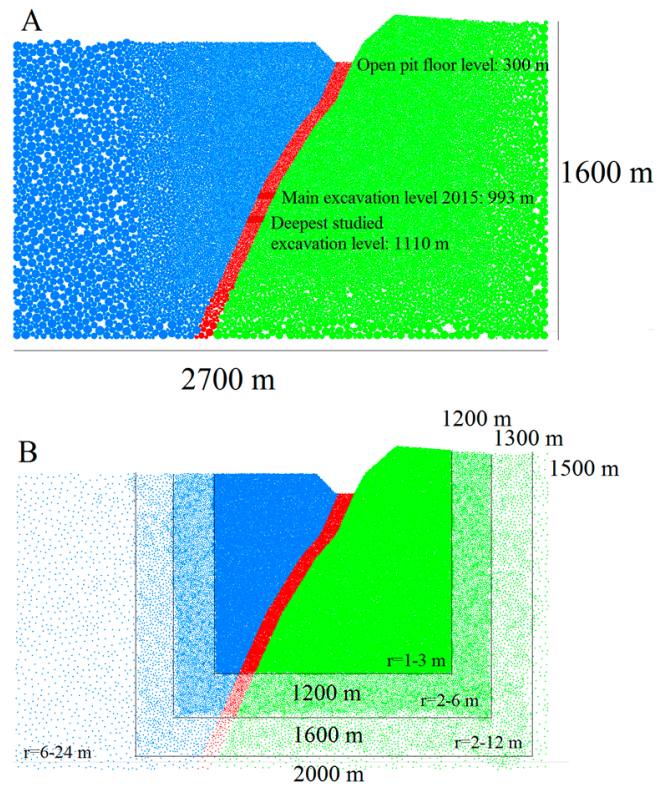

Figure 5. (A) Geometry of the PFC model divided into hanging wall (blue), ore (red) and footwall (green). (B) Size regions for constitutive particles.

To calibrate the rock mass properties, a calibration volume was defined as a rectangle with $100 \mathrm{~m}$ width and $200 \mathrm{~m}$ height. This volume corresponds both to the calibration volume used for the PFC model used by Villegas and Nordlund [3] and the volume indicated to be of interest for the extension of the damaged zone in the footwall from the ore contact to the constant portion of the damage extent boundary [5].

A "rock core" was cut from the footwall at a depth of $700 \mathrm{~m}$ close to the ore contact with the dimensions of $240 \mathrm{~m}$ in height and $100 \mathrm{~m}$ in width. The uppermost and lowermost $20 \mathrm{~m}$ were re-grouped as pressure plates resulting in a final "test core" with dimensions of $100 \mathrm{~m}$ by $200 \mathrm{~m}$, see Figure 6. The pressure plates were added to ensure a more uniform loading of the sample by a "perfect fit" of the pressure plates to the surface undulation resulting from the disc-shaped particles making up the matrix. 


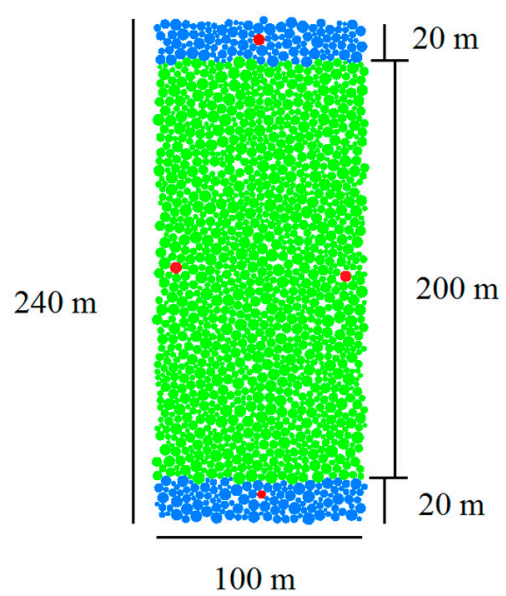

Figure 6. Test core cut from the footwall (green) including pressure plates (blue) and positions for displacement tracking (red).

The micro-properties of the sample were calibrated by UCS testing until the macro-properties fell within the range estimated for the rock mass from the field data as summarized in Table 2 . The sample was examined with respect to the elastic properties $E$ and $v$ and the uniaxial peak compressive strength. The elastic constants were evaluated using the displacement tracking points indicated in Figure 6. The relative displacements of the measured particles during testing were used in the same way as a strain gauge to measure the axial and radial straining of the sample. The sample was loaded in a gravitation-free environment to avoid failure from the sample self-weight. Loading was achieved by fixing the upper pressure plate against an immobile wall and pushing the lower pressure plate by a second wall displaced at a rate of $5 \mathrm{~mm} / \mathrm{s}$ past complete sample failure.

The final results from the calibration campaigns are shown in Table 2 and Figure 7. The footwall target values were set to correspond to the input values derived by Svartsjaern et al. [5]. A second set of parameters resulting in a 30\% lowering of the $\mathrm{UCS}_{r m}$ was also determined to investigate the impact of accounting for the perceived relative strength difference between the footwall and hanging wall. The elastic constants for the two sets are similar; for both samples the Poisson's ratio is initially stable until about $20 \%$ UCS, after which it starts to increase until sample failure at $10-15 \%$ above the initial value. This increase in Poisson's ratio during loading is likely caused by the formation of new non-coalescent fractures inside the sample due to bond breakage, as described by Gercek [26]. Similarly, the Young's modulus increases for the same range with about $10 \%$ during sample loading. Table 2 contains the initial values.

Table 2. Calibrated micro-mechanical properties and resulting macro-properties.

\begin{tabular}{|c|c|c|c|c|c|c|c|c|c|}
\hline \multirow[b]{2}{*}{ Property } & \multicolumn{3}{|c|}{ Micro-Properties (Bond) } & \multicolumn{3}{|c|}{ Micro-Properties (Contact) } & \multicolumn{3}{|c|}{ Macro-Properties } \\
\hline & $c(\mathrm{MPa})$ & $\phi\left({ }^{\circ}\right)$ & $\begin{array}{c}\sigma_{t} \\
(\mathrm{MPa})\end{array}$ & $E(\mathrm{GPa})$ & $\begin{array}{c}K_{\mathrm{n}} / K_{\mathrm{s}} \\
\text { (Ratio) }\end{array}$ & $\begin{array}{l}\text { De-Bonded } \\
\text { Friction } \\
\text { Coefficient }\end{array}$ & $\begin{array}{c}E_{r m} \\
(\mathrm{GPa})\end{array}$ & $\begin{array}{c}v_{r m} \\
\text { (Ratio) }\end{array}$ & $\begin{array}{l}\mathrm{UCS}_{r m} \\
\text { (MPa) }\end{array}$ \\
\hline Rock mass range & - & - & - & - & - & - & $3.4-25$ & $0.27-0.35$ & $5-9$ \\
\hline Footwall target & - & - & - & - & - & - & 18 & 0.27 & 4.7 \\
\hline Footwall PFC & 27 & 36 & 27 & 36 & 0.25 & 1.0 & 18 & 0.28 & 4.6 \\
\hline Hanging wall target & - & - & - & - & - & - & 18 & 0.30 & 3.3 \\
\hline Hanging wall PFC & 24 & 36 & 21.6 & 36 & 0.25 & 1.0 & 18 & 0.31 & 3.3 \\
\hline Pressure plates & $10^{44}$ & 36 & $10^{44}$ & 100 & 0.25 & 1.0 & - & - & - \\
\hline
\end{tabular}




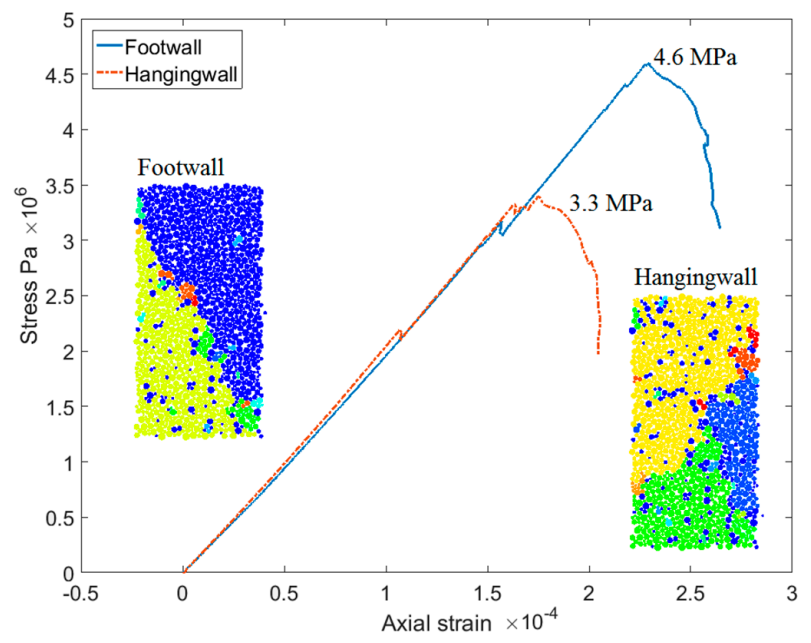

Figure 7. Final numerical $\mathrm{UCS}_{r m}$ results including failed test-cores.

\subsection{PFC Mining Sequence}

The data from Table 2 are input to the model in Figure 5. A "stress probe" is overlaid on the entire future mining volume by a sphere with radius $520 \mathrm{~m}$ centred in the footwall so the top of the sphere overlaps the open pit floor. The average stress inside the sphere is calculated and the right and left boundaries of the model are pushed together until the vertical to horizontal stress ratio equals 0.78 . The material state is "reset" by reapplying any broken bonds.

The SLC is mined from the open pit floor, past the current (2014-2016) main mining level at $993 \mathrm{~m}$ down to $1110 \mathrm{~m}$ (four additional sublevels), as in Figure 5. Each sublevel is excavated in five cuts from the hanging wall to the footwall with the model run to equilibrium for each cut (see Figure 8). The open pit floor is not mined apart from a single slice to prevent an ore pillar from forming. A total of 129 mining steps are performed, where each step removes 35-45 particles with an in-plane footprint of 20 by $30 \mathrm{~m}\left(600 \mathrm{~m}^{2}\right)$ for mid-ore sections and 15-25 particles with a triangular footprint of $200-400 \mathrm{~m}^{2}$ at the ore-contacts.

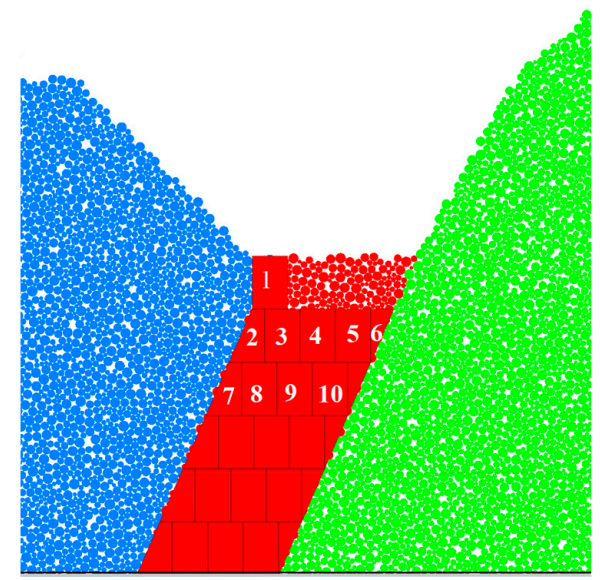

Figure 8. Principle of excavation order starting from ground surface (pit floor) with the individual excavation areas (vertical footprints) in red.

\section{Results and Comparison to Current Damage Patterns and Deformation States}

Two model setups are run based on the parameters from Table 2: Case A, where the same footwall rock mass properties are allocated for the hanging wall and footwall as well as the orebody, and Case 
B, where the footwall and orebody are allocated footwall properties and the hanging wall is allocated the lower strength properties estimated for this volume.

The footwall rock mass contains accessible underground infrastructure, which allows the response to mining be studied underground as well as on the ground surface. For the ground surface subsidence both the field data and the numerical results show negligible movement of the ground surface at the footwall crest. However, damage mapping of the underground infrastructure indicate rock mass deformation in the footwall underground [17].

The comparison between Cases A and B shows a clear reaction in the footwall from "changing" the hanging wall strength. The weaker hanging wall in Case B caves more readily, resulting in a wider cave zone (Figure 9). The wider cave zone entails a lower buttressing pressure on the footwall and the particle un-bonding reaches farther into the footwall, which allows for more horizontal displacements in Case B than in the more confined Case A.

The ground surface subsidence measurements on the hanging wall indicate that the magnitudes of displacements in the numerically modelled cases might be underestimated. However, the deformation pattern indicates the existence of a mobilised zone close to the footwall contact which does not reach the footwall crest. The horizontal components in this mobilised zone are plotted together with the damage extent boundary (DEB) defined by Svartsjaern et al. [5] in Figure 10. There is a correlation between the extent of this mobilised zone, the DEB and the unbounded particles in the footwall (Figure 9) most notably between levels 509 and $740 \mathrm{~m}$. Unfortunately, section Y23 is not accessible between $907 \mathrm{~m}$ and the current excavation levels of 993 and $1020 \mathrm{~m}$; the DEB is thus not defined below $907 \mathrm{~m}$. Damage mapping on other sections of the mine indicate that the DEB intersects with the SLC 100-150 m above the production level. The extent of fracturing at depth in the model cases is thus not interpreted as indicative of the current position of the DEB.

The relation between the active fracturing zone below the production level indicated by seismic records as described by Svartsjaern and Eitzenberger [27], the extent of bond breakage in the modelled cases, and the development of the DEB are conceptually described in Figure 11. Rock mass damage primarily accumulates at, and beneath, the production level, but high confining pressures immobilises the blocks. As the production goes deeper, the widening SLC gradually de-stresses the footwall, causing rock falls and other damages in the infrastructure defined by the earlier rock mass deterioration. This evolution path of the DEB clearly advocates the importance of the cave rock backpressure on the footwall stability as the width of the SLC relates to the in-wall depth of the DEB. There is thus a strong argument for including the hanging wall caving behaviour when attempting to forecast damage development in the footwall.

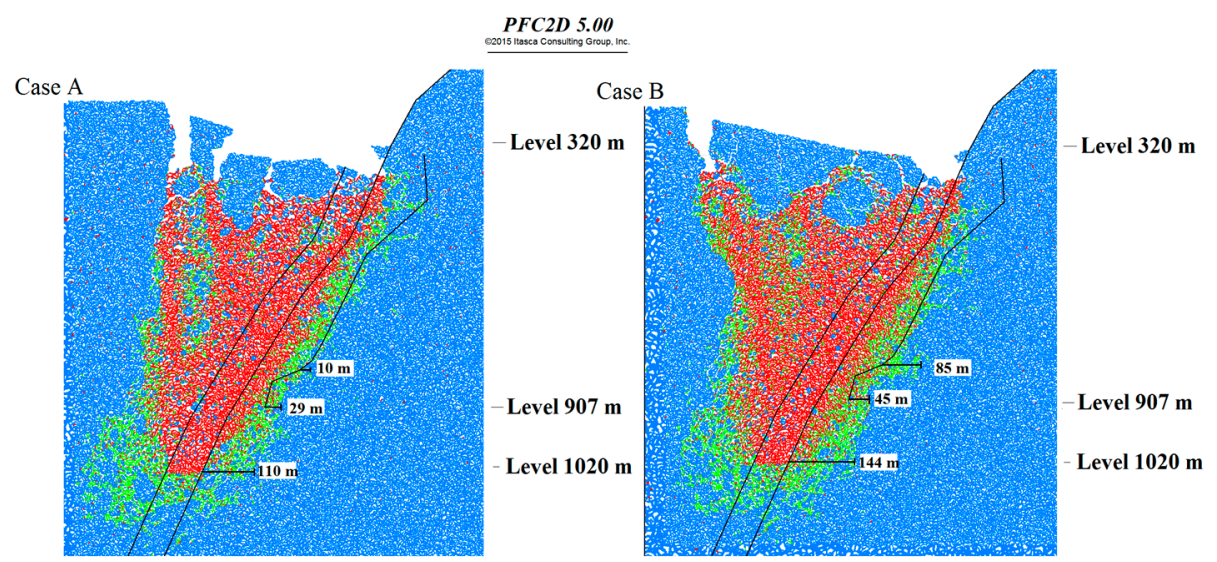

Figure 9. Parallel bond state for Cases A and B after mining at $1020 \mathrm{~m}$ (the current lowest opened excavation level) and above; the blue matrix is un-yielded while red and green show broken bonds; the black line indicate the position of the damage extent boundary. 


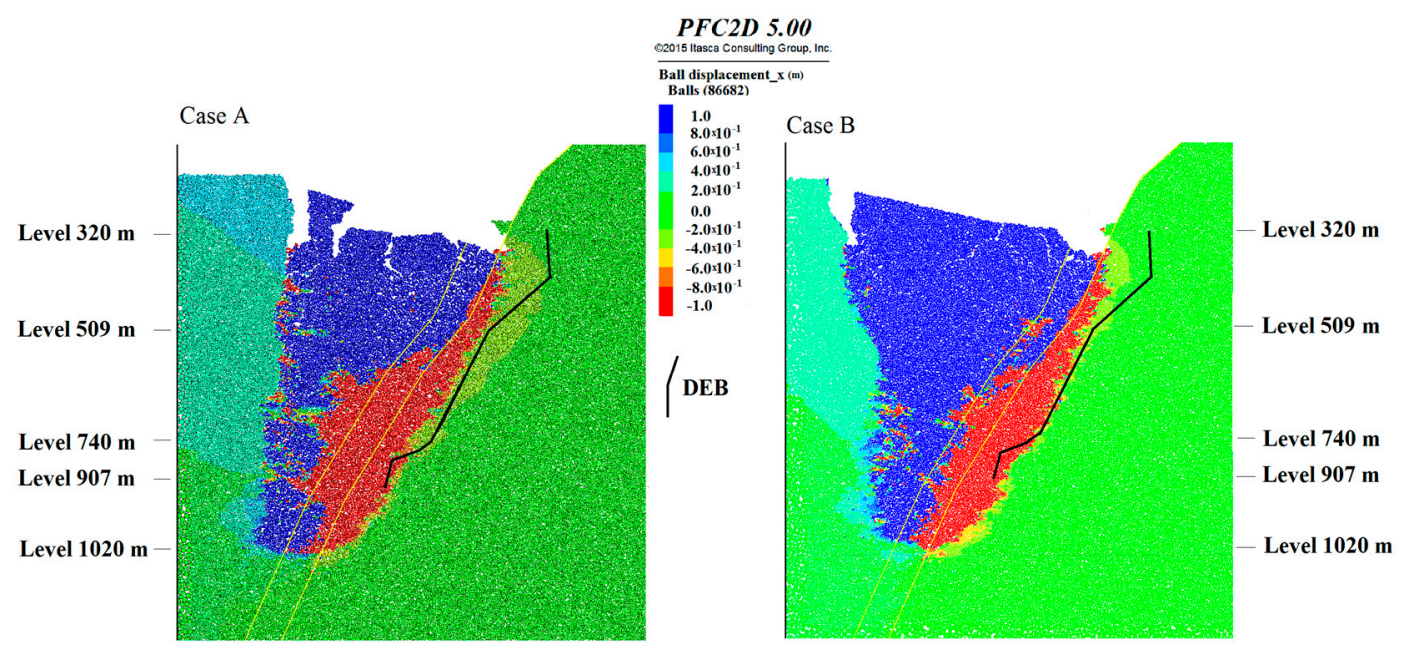

Figure 10. Horizontal displacements for Cases A and B after mining at $1020 \mathrm{~m}$ (the current lowest opened excavation level) and above; the black line indicates the position of the damage extent boundary defined from field mapping.
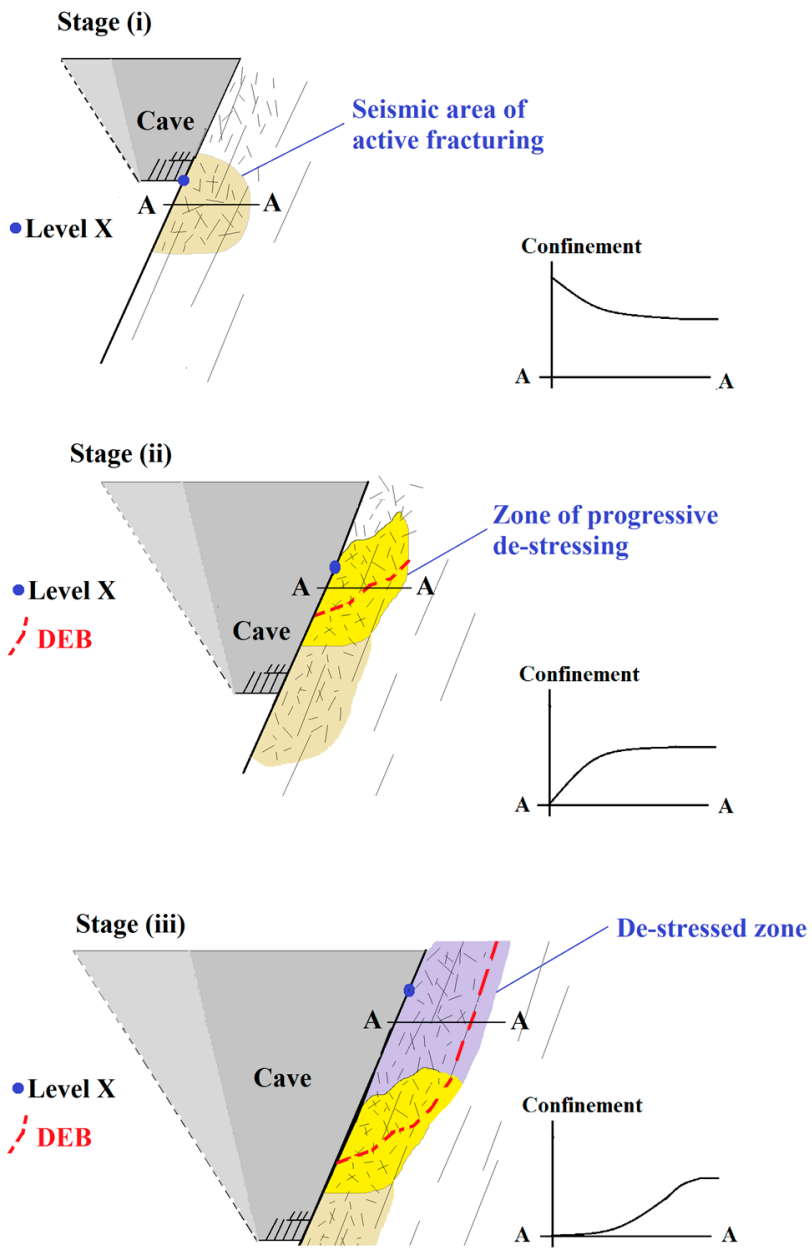

Figure 11. Interpreted evolution of the footwall DEB related to rock mass deterioration at the production level and the relative confinement from the hanging wall and SLC.

On the hanging wall there is no relevant accessible infrastructure underground; trends in the modelling results are therefore compared to the ground surface response to mining for the two model 
cases, $\mathrm{A}$ and $\mathrm{B}$. The model comprises a 2D section along the east-west $\mathrm{X}$-axis set at Y23; the relative position of this section to the closest GPS subsidence measurement line, the position of the current cave limit, and the nearby surface features are shown in Figure 12. The closest GPS line constitutes nine individual points designated P1 to P9, where P1 lies closest to the cave limit and P9 farthest away, with the cave limit defined as the western-most point on the hanging wall crest considered stable enough to walk to in the field.

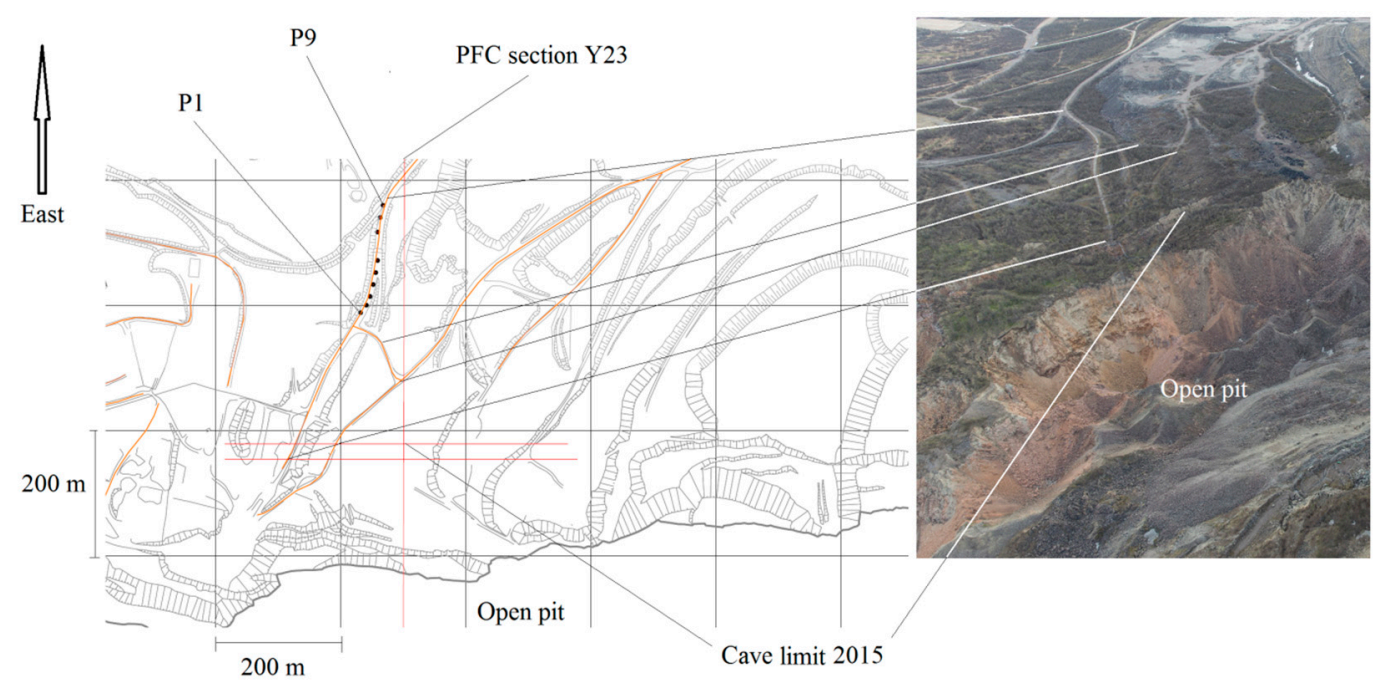

Figure 12. Surface features and position of subsidence measurements on the hanging wall, section Y23.

Comparison between the field ground surface observations and the modelling results shows that the full range of the hanging wall behaviour is not well represented in either of the two modelled cases. However, some of the principal trends and mechanisms are replicated by Case A for the current deformation state.

After caving is initiated, Case A shows a tendency towards toppling near the cave limit as slabs of the rock mass matrix cave from the hanging wall in vertical rectangles that rotate into the cave zone, which corresponds the field descriptions by Villegas and Nordlund [3]. However, due to the use of a non-jointed equivalent continuous in situ material in the models, caving of the hanging wall does not correspond to the start of underground mining. Caving of the hanging wall begins after mining at $630 \mathrm{~m}$ (corresponding to roughly 1992) and the location of the cave limit is overestimated by about $100 \mathrm{~m}$ compared to the location reported by Lupo [9]. The Case A cave limit remains stationary until mining at $840 \mathrm{~m}$ (year 2004), during which it moves $90 \mathrm{~m}$. Interpolation between the 2015 field cave limit and that reported for 1994 by Lupo [9] indicates that the Case A cave limit again overestimates the cave limit position by about $100 \mathrm{~m}$. The actual cave limit in the field continues to progress while the Case A limit remains stationary, resulting in the model case and field observation lining up for the 2015 excavation of level $990 \mathrm{~m}$ and opening of level $1020 \mathrm{~m}$. Also for Case B, caving beings after mining of several sublevels; again the cave limit location remains stationary for several excavation steps followed by a significant move. The Case B cave limit position is determined by the caving of one single massive block, which overestimates the position for excavation stages. At the current deformation state, Case B overestimates the cave limit position by almost $200 \mathrm{~m}$ (see Figure 13). 
Case A

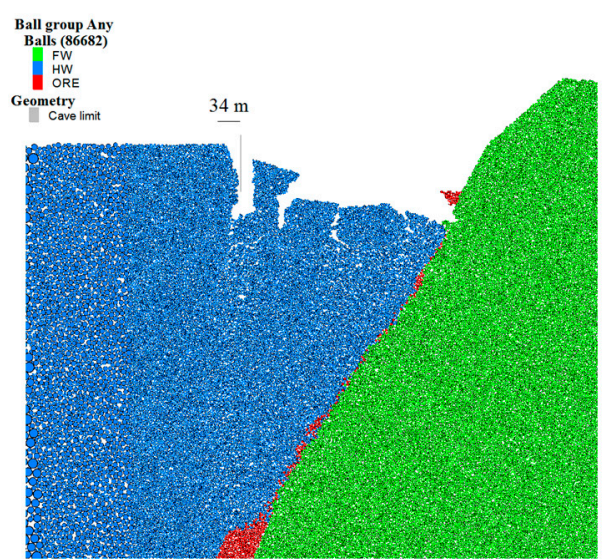

Case B

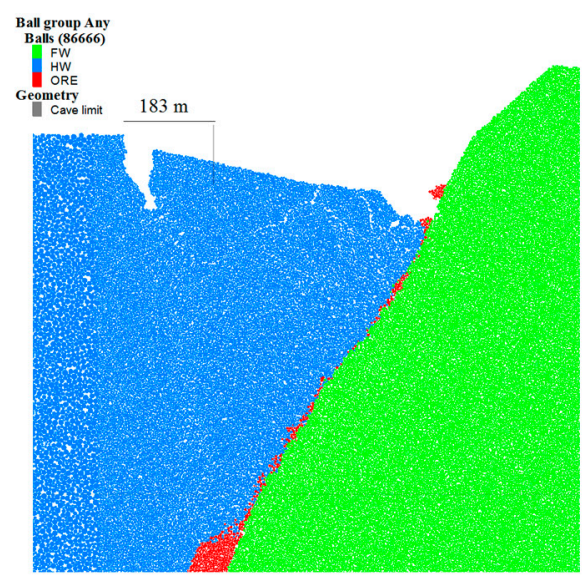

Figure 13. Numerical results for Cases A and B with ground surface footprint after excavating at $1020 \mathrm{~m}$ (the current lowest opened excavation level) and 2015 field cave limit position.

The deformation state in the elastic region ahead of the cave limit at the location of the P1-P9 GPS line for both modelled cases and the corresponding field measurements are shown in Figure 14 for the GPS line and Figure 15 for the individual measuring point locations. It is clear that there are similarities in the trends for the three cases (field case and numerical cases A and B), but the magnitude of deformations indicated by the numerical results are approximately 10 times lower. Cases $\mathrm{A}$ and $B$ produce similar results but Case A indicates an acceleration of surface subsidence as the mining continues (the curved line in Figure 15) while Case B indicates steady state subsidence for the same period (the almost-straight line in Figure 15). The field data for the same period show steady state subsidence between 2005 and 2013, followed by accelerated deformation between 2013 and 2015 . All cases (numerical and field) show increasing subsidence when moving along the GPS line from P9 to P1 for the period 2011-2015 (the left-inclined trends in Figure 14).
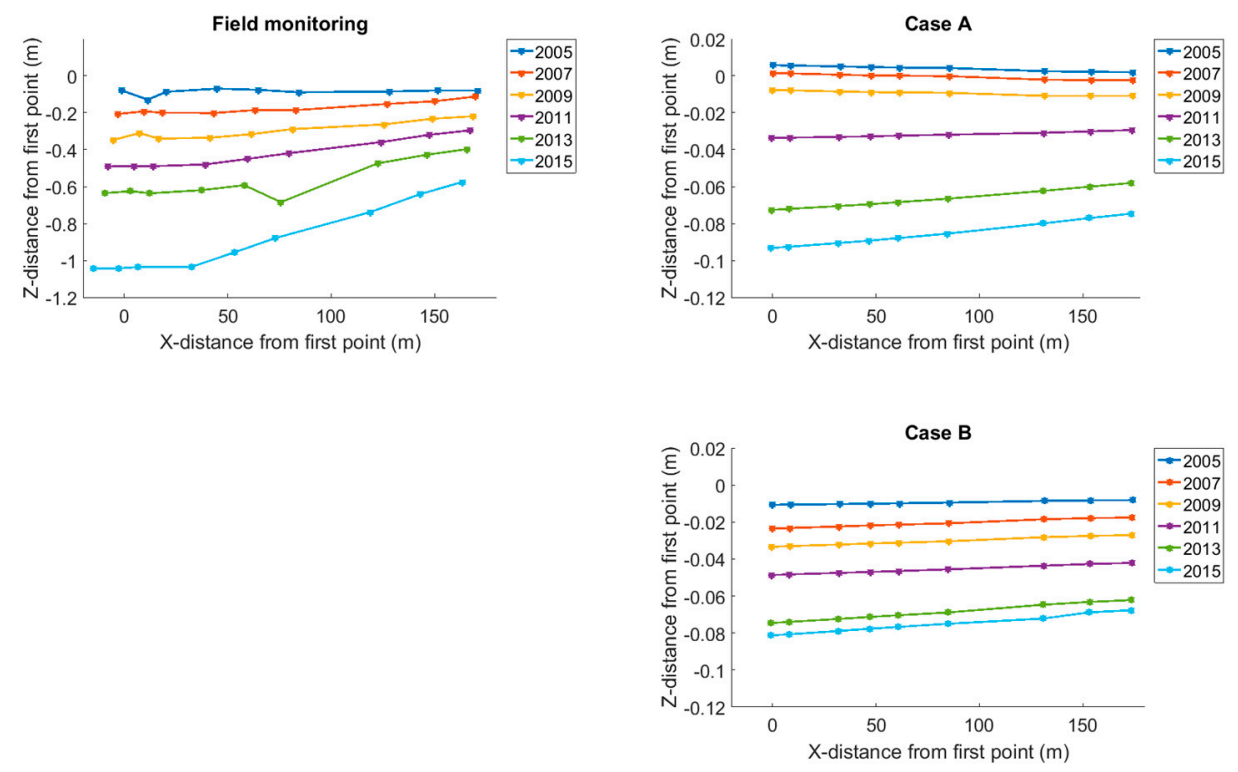

Figure 14. Subsidence data for lines P1-P9 relative to a common "zero reading" in 2003, i.e., the excavation of level $849 \mathrm{~m}$ is used as relative origin; note the difference in Y-axis scale between the field and numerical graphs. X-deformations have in all plots been scaled with a multiplier of 10 to be visible. 

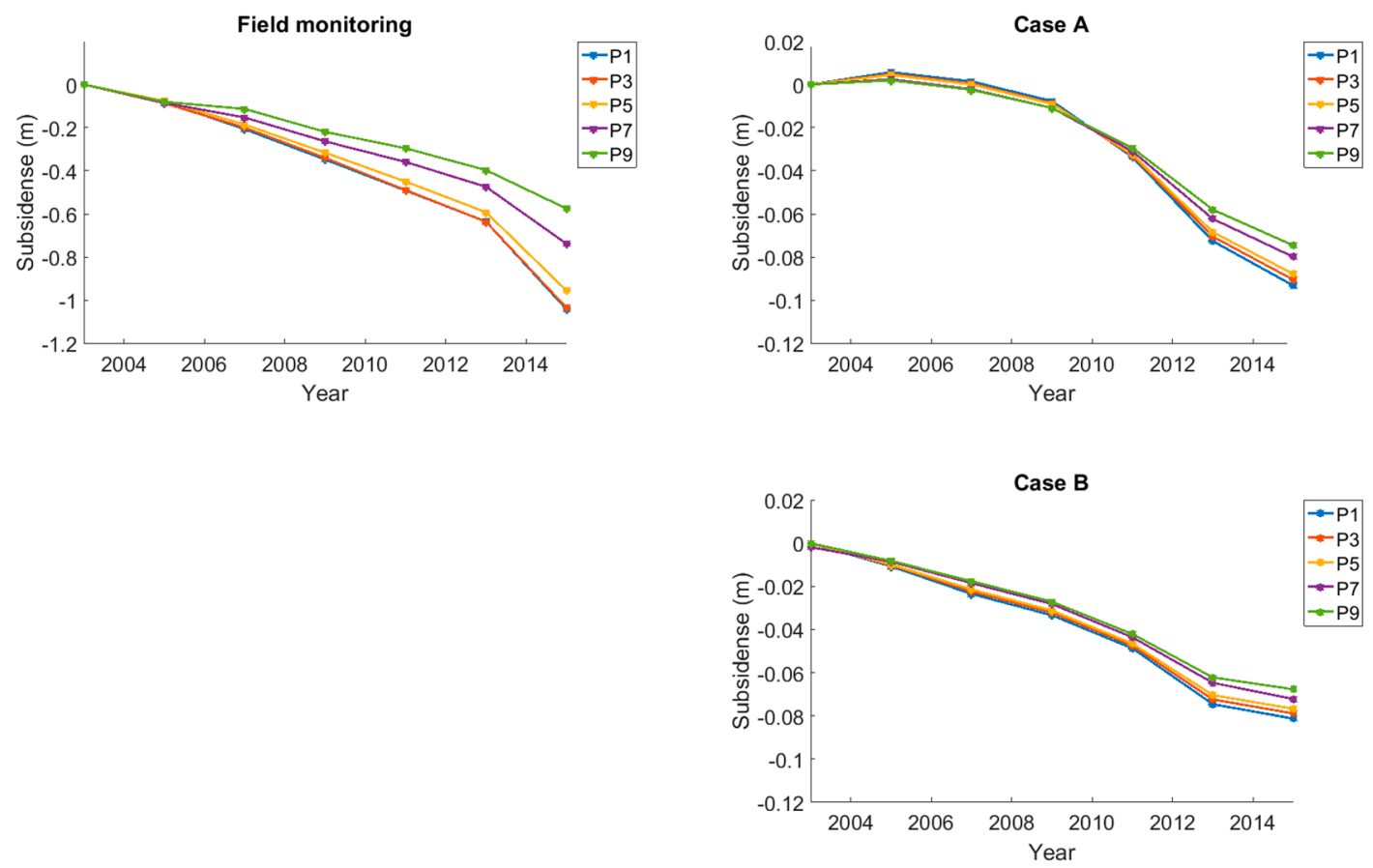

Figure 15. Subsidence data for the individual points P1, P3, P5, P7, and P9 relative to a common "zero reading" in 2003, i.e., the excavation of level $849 \mathrm{~m}$ is used as relative origin, note the difference in Y-axis scale between the field and numerical graphs.

\section{Discussion}

The rock mass parameters used for this study were based on two types of data sources; (i) measurement data, e.g., UCS combined with rock mass classifications from field data; and (ii) back analysis of damage observations reported in previous studies of the mine. It goes without saying that the preferable case would have been to directly input measured quantities into the model and replicate field results. However, due to the scale difference between what is commonly measured in laboratories and in the field ( $\mathrm{mm}$ to $\mathrm{m}$ scale) and the mine scale (hundreds to thousands of $\mathrm{m}$ ), some features must be scaled, some neglected in the simplification process, and others are simply unknown. To address the scaling issue, the geological properties known for the intact rock and the rock mass classification results were used to suggest plausible ranges for the geomechanical properties from the back-analysed cases.

The rock mass in the modelled cases was represented as a cemented granular matrix (BPM in PFC), initially set up as a homogeneous material that was later allowed to fracture in response to mining stresses. The in situ rock joints were accounted for indirectly by scaling of the target rock mass strength using GSI and RMR values from the field. With this approach the strength reduction of the rock mass relative to the expected strength of an intact rock core sample was achieved but the directional dependence or anisotropy related to the major joint sets was lost. From the results of this study, it is reasonable to assume that this anisotropy might be an important factor in the caving behaviour of the hanging wall as the failure mode of the hanging wall involves the propagation and opening of large-scale discontinuities outlining toppling blocks. However, while not covering the full range of the caving behaviour, the applied PFC model does allow the cave material to form explicitly from the hanging wall caving, which directly models the pressures and internal material flow within the cave zone. The footwall failure mode, which was the primary focus of this study, involves the creation of many short and multi-directionally oriented fractures during stress rotation below and at the production level, making it much less dependent on the coalescence of anisotropic planes. The step-by-step mining sequence applied, in combination with the large number of bonded-particles, was 
associated with significant computational time. In all, using a high-performance office desktop, the complete mining cycle runs for about three weeks. In a case when the expected failure pattern would be affected more by semi-persistent discontinuity planes with an expected coherent failure surface reaching the ground surface by, e.g., the development of a step-path failure, computation time could likely be decreased by application of a hybrid method such as FEM/DEM rather than a pure DEM approach (e.g., [28,29]). This approach is, however, dependent on the quality of the applied DFN [30].

Two model cases were run to study the impact of the caving behaviour of the hanging wall on the footwall failure. In Case A the hanging wall $\mathrm{UCS}_{r m}$ was set to be equal to the scaled strength of the footwall and in Case B the UCS $\mathrm{UCm}_{r m}$ of the hanging wall was lowered by $30 \%$. While the second, lower, value used in Case B was not derived directly from field data, it is considered to be reasonable from a comparison standpoint as previous studies indicate that the hanging wall is less competent than the footwall (e.g., [3,15]). Thus, by retaining the strength values for the footwall and at the same time lowering the values for the hanging wall, the significance of the backpressure from the hanging wall cave rock on damage development in the footwall could be studied by comparing Cases A and B. The possible importance of this relationship for the footwall stability as well as the large number of unknowns related to the cave rock has been highlighted by previous research [6,23].

Case A came close to the current in situ hanging wall cave limit, which suggests that the width and flow of the cave rock zone was adequately simulated at the current mining stage. The cave rock zone in Case B was much wider than that suggested by Case A and the field estimate. The comparison of the two modelled cases showed that the extent and pattern of damage in the footwall rock mass are dependent not only on the footwall strength but also on the hanging wall strength. Future studies of rock mass damage in the footwall rock mass thus need to focus on both the hanging wall strength and the footwall strength in any effort using damage patterns as the basis for calibration.

The elastic deformation ahead of caving on the hanging wall was not well captured by either modelled case. Case A arguably replicates the development of steps and chimneys at the inner edge of the discontinuous deformation zone, but does not capture the small-scale tensile fractures forming ahead of the cave limit, as the fractures that do form coalesce rapidly to facilitate the cave limit toppling. The expected transition between the discontinuous and continuous deformation zones, and thus the break angle of the operation, cannot be readily determined for the modelled case. As described earlier, it is plausible that this model limitation is related to the equivalent homogeneous material approach. The anisotropic behaviour related to natural joint planes likely has a significant impact on the near ground surface behaviour of the hanging wall as the material strives to shift towards the cave zone. The lack of such distinct weakness planes means that the model caves less readily and breaks into blocks larger than expected from field observations. This also means that the deformations ahead of caving in the model cases are purely elastic, the plastic component from joint opening in the field is neglected and the resulting deformations are much smaller than the actual response on site.

\section{Conclusions}

The rock mass response to mining at the Kiirunavaara mine was studied using PFC. The equivalent rock mass input was estimated using a combination of measured data, rock mass classification results and back analysis data from previous studies. The model response was evaluated related to observations from both the hanging wall and footwall and the impact on footwall damage from varying the hanging wall strength was studied. The major conclusions of this study are:

- Geomechanical parameters derived from back analysis of damage observed both for the hanging wall and the footwall indicate lower rock mass strength than values from empirical scaling of intact material properties by rock mass classification. Geological data were used, together with the rock mass classifications, to find the upper and lower limits for the geomechanical parameters derived from back analysis of damage locations. The resulting input was used in a model shown to be capable of capturing damage location and subsidence trends but not subsidence magnitudes. 
- There is a clear relationship between the strength of the hanging wall and the damage in the footwall. A wider cave zone resulting from a relatively weaker model of the hanging wall produces more deeply seated damage in the footwall than a narrower cave zone.

- The damage in the footwall underground infrastructure is not the result of a coherent large-scale footwall failure but a symptom of local rock mass damage, which forms a large-scale pattern.

- The full range of hanging wall caving behaviour was not well represented by the applied equivalent homogeneous material approach. It is likely that the anisotropy related to natural joint sets plays an important role at the cave limit. Future models should thus strive to account for this if a better representation of the cave development is sought.

Acknowledgments: The author acknowledges the funding and right to publish granted for this study by LKAB. Thanks are also due to Centre of Mining and Metallurgy (CAMM) at Luleå University of Technology (LTU). The author also acknowledge the on-site contributions during data collection by LKAB research staff in particular Karola Mäkitaavola, Britt-Mari Stöckel, Åke Öhrn, Erik Swedberg (formerly LKAB), Mirjana Boskovic and Håkan Krekula (formerly LKAB). Finally, thanks are due to Andreas Eitzenberger (LTU) and Adjunct Professor Jonny Sjöberg (Itasca Consultants AB) for valuable comments throughout the study underlying this paper.

Author Contributions: The first author carried out the field work, the analysis and authored the paper. The second author aided in the interpretation of the results and corrected the draft version of the manuscript.

Conflicts of Interest: There are no conflicts of interest.

\section{References}

1. Stöckel, B.M.; Mäkitaavola, K.; Sjöberg, J. Hangingwall and footwall slope stability issues in sublevel caving. Proc. Slope Stab. 2003, 1045-1060.

2. Villegas, T.; Nordlund, E. Numerical simulation of the hangingwall subsidence using PFC2D. In Proceedings of the 5th International Conference and Exhibition on Mass Mining, Luleå, Sweden, 9-11 June 2008.

3. Villegas, T.; Nordlund, E. Numerical analyses of the hangingwall failure due to sublevel caving: Study case. Int. J. Min. Miner. Eng. 2013, 4, 201-223.

4. Henry, E.; Dahnér-Lindqvist, C. Footwall stability at the LKAB's Kiruna sublevel caving operation, Sweden. In Proceedings of the 3rd International Conference and Exhibition on Mass Mining, Brisbane Australia, 29 October-2 November 2000.

5. Svartsjaern, M.; Saiang, D.; Nordlund, E.; Eitzenberger, A. Conceptual numerical modeling of large scale footwall behavior at the Kiirunavaara mine, and implications for deformation monitoring. Rock Mech. Rock Eng. 2016, 49, 943-960. [CrossRef]

6. Eniro. Website and Map Service. Available online: http://kartor.eniro.se (accessed on 8 April 2016).

7. Sjöberg, J. Analysis of Large Scale Rock Slopes. Ph.D. Thesis, Luleå University of Technology, Lulea, Sweden, 1999.

8. Villegas, T.; Nordlund, E.; Dahnér-Lindqvist, C. Hangingwall surface subsidence at the Kiirunavaara Mine, Sweden. Eng. Geol. 2011, 121, 18-27. [CrossRef]

9. Lupo, J.F. Evaluation of Deformations Resulting from Mass Mining of an Inclined Orebody. Ph.D. Thesis, Colorado School of Mines, Golden, CO, USA, 1996.

10. Itasca Consulting Group Inc. PFC 5.0 Documentation. Itasca Consulting Group Inc.: Minneapolis, MN, USA, 2015.

11. Malmgren, L.; Sjöberg, J. Bergmekaniska Analyser för ny Huvudnivå KUJ; Internal Document; LKAB: Luleå, Sweden, 2006. (In Swedish)

12. Sandström, D. Analysis of the Virgin State of Stress at the Kiirunavaara Mine. Licentiate Thesis, Luleå University of Technology, Lulea, Sweden, 2003.

13. Mattsson, H.; Berglund, J.; Magnor, B. Strukturgeologisk Modell över Kiruna Gruvområde; Internal Document; LKAB: Luleå, Sweden, 2010. (In Swedish)

14. Sjöberg, J.; Lundman, P.; Nordlund, E. Analys Och Prognos av Utfall i Bergschakt, KUJ 1045 Slutrapport; Internal Document; LKAB: Luleå, Sweden, 2001. (In Swedish)

15. Vatcher, J.; McKinnon, S.D.; Sjöberg, J. Developing 3-D mine-scale geomechanical models in complex geological environments, as applied to the Kiirunavaara Mine. Eng. Geol. 2016, 203, 140-150. [CrossRef] 
16. Villegas, T. Numerical Analyses of the Hangingwall at the Kiirunavaara Mine. Licentiate Thesis, Luleå University of Technology, Luleå, Sweden, 2008.

17. Svartsjaern, M.; Saiang, D.; Mäkitaavola, K. Underground footwall monitoring at the Kiirunavaara SLC mine, Sweden. In Proceedings of the Seventh International Conference and Exhibition on Mass Mining, Sydney Australia, 9-11 May 2016.

18. Mas Ivars, D. Bonded Particle Model for Jointed Rock Mass. Ph.D. Thesis, Royal Institute of Technology, Stockholm, Sweden, 2010.

19. Potyondy, D.O.; Cundall, P.A. A bonded particle model for rock. Int. J. Rock Mech. Min. Sci. 2004, 41, 1329-1364. [CrossRef]

20. Dahnér-Lindqvist, C. Liggväggstabiliteten i Kiirunavaara; Bergmekanikdagen: Stockholm, Sweden, 1992; pp. 37-52. (In Swedish)

21. Singh, U.K.; Stephansson, O.J.; Herdocia, A. Simulation of progressive failure in hangingwall and footwall for mining with sub-level caving. Trans. Inst. Min. Metall. 1993, 102, 188-194.

22. Lupo, J.F. Numerical simulation of progressive failure from underground bulk mining operations. In Proceedings of the 37th U.S. Symposium on Rock Mechanics Rotterdam, Vail, CO, USA, 7-9 June 1999; pp. 1085-1090.

23. Sitharam, T.G.; Madhavi Latha, G. Simulation of excavations in jointed rock masses using a practical equivalent continuum approach. Int. J. Rock Mech. Min. Sci. 2002, 39, 517-525. [CrossRef]

24. Hoek, E.; Carranza-Torres, C.; Corkum, B. Hoek-Brown Failure Criterion-2002 Edition. In Proceedings of the 5th North American Rock Mechanics Symposium and 17th Tunneling Association of Canada Conference, Toronto, ON, Canada, 7-10 July 2002; Volume 1, pp. 267-271.

25. Hoek, E.; Diederichs, M. Empirical estimation of rock mass modulus. Int. J. Rock Mech. Min. Sci. 2006, 43, 203-215. [CrossRef]

26. Gercek, H. Poisson's ratio values for rocks. Int. J. Rock Mech. Min. Sci. 2007, 44, 1-13. [CrossRef]

27. Svartsjaern, M.; Eitzenberger, A. Determination of magnitude completeness from convex Gutenberg-Richter graphs in the central portion of the Kiirunavaara mine. J. S. Afr. Inst. Min. Metall. 2017, in press.

28. Vyazmensky, A.; Stead, D.; Elmo, D.; Moss, A. Numerical Analysis of Block Caving-Induced Instability in Large Open Pit Slopes: A Finite Element/Discrete Element Approach. Rock Mech. Rock Eng. 2010, 43, 21-39. [CrossRef]

29. Vyamensky, A.; Elmo, D.; Stead, D. Role of Rock Mass Fabric and Faulting in the Development of Block Caving Induced Surface Subsidence. Rock Mech. Rock Eng. 2010, 43, 533-556. [CrossRef]

30. Lei, Q.; Latham, J.-P.; Xiang, J.; Tsang, C.-F.; Lang, P.; Guo, L. Effects of geomechanical changes on the validity of a discrete fracture network representation of a realistic two-dimensional fractured rock. Int. J. Rock Mech. Min. Sci. 2014, 70, 507-523. [CrossRef]

(c) 2017 by the authors. Licensee MDPI, Basel, Switzerland. This article is an open access article distributed under the terms and conditions of the Creative Commons Attribution (CC BY) license (http://creativecommons.org/licenses/by/4.0/). 